\title{
Optimal Monetary Policy with \\ Overlapping Generations of Policymakers
}

\author{
Maral Shamloo
}




\title{
IMF Working Paper
}

\author{
IMF Institute
}

\section{Optimal Monetary Policy with Overlapping Generations of Policymakers}

\author{
Prepared by Maral Shamloo ${ }^{1}$
}

Authorized for distribution by Alex Mourmouras

) HEXDY 2010

\begin{abstract}
This Working Paper should not be reported as representing the views of the IMF.

The views expressed in this Working Paper are those of the author(s) and do not necessarily represent those of the IMF or IMF policy. Working Papers describe research in progress by the author(s) and are published to elicit comments and to further debate.

In this paper I study the effect of imperfect central bank commitment on inflationary outcomes. I present a model in which the monetary authority is a committee that consists of members who serve overlapping, finite terms. Older and younger generations of Monetary Policy Committee (MPC) members decide on policy by engaging in a bargaining process. I show that this setup gives rise to a continuous measure of the degree of monetary authority's commitment. The model suggests that the lower the churning rate or the longer the tenure time, the closer social welfare will be to that under optimal commitment policy.

JEL Classification Numbers:E52; E58; E61

Keywords: Monetary Policy Committee, Commitment, Discretion, Optimal Monetary Policy

Author's E-Mail Address:mshamloo@imf.org

\footnotetext{
${ }^{1}$ This work is based on chapter 2 of my PhD thesis at the LSE. I would like to thank my advisor, Kosuke Aoki, for his invaluable advice and continued support. I am grateful to friends and faculty members at the LSE and colleagues at the IMF for their insightful comments. Francesco Caselli, Valerie Cerra, Eric Clifton, Tom Cunningham, Enrica Detragiache, Aytek Malkhozov, Alex Mourmouras, Chris Pissarides, Kevin Sheedy, Silvana Tenreyro and David Webb were among them. All errors are mine.
} 


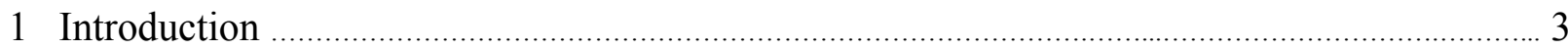

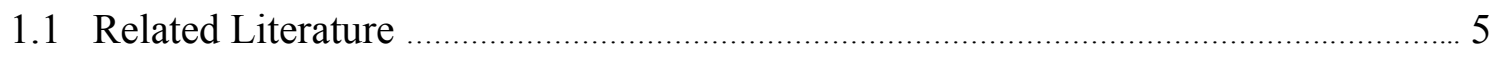

2 Optimal Monetary Policy: The New Keynesian Framework ……........................................ 8

2.1 Optimal Monetary Policy and Stabilization Bias …................................................ 8

2.2 Optimal Response under Discretion ........................................................................ 9

2.3 Optimal Response under Commitment .................................................................... 10

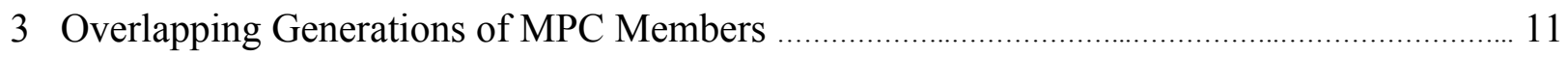

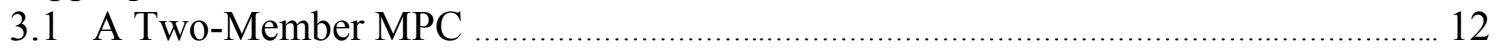

3.2 The Bargaining Process .................................................................................................. 13

3.2.1 The Bargaining Problem …................................................................................. 14

3.2.2 The Utilitarian Solution and the Stationary Equilibrium .......................... 14

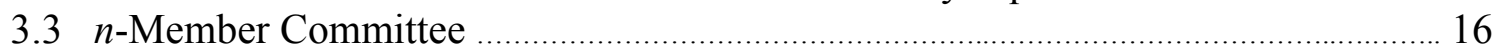

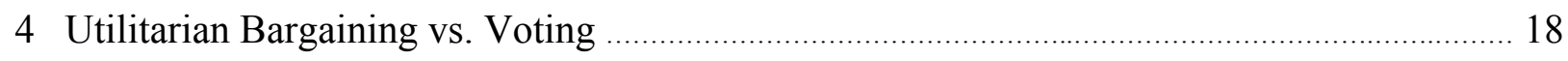

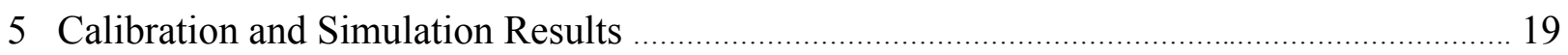

5.1 Impulse Responses to Independent Shocks .............................................................. 19

5.2 Impulse Responses to Persistent Shocks ................................................................... 21

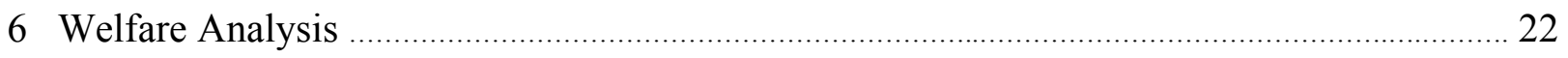

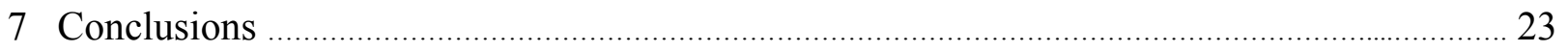

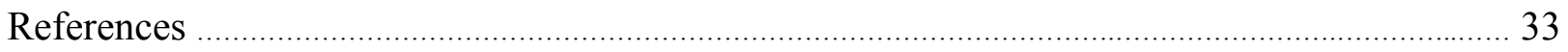

Tables

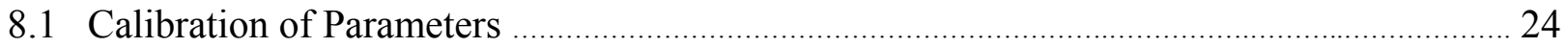

Figures

9.1 Dynamic Response to a Cost-push Shock …........................................................................... 25

9.2 Dynamic Response to a Cost-push Shock: Committee …................................................... 26

9.3 Dynamic Response to a Persistent Cost-push Shock …......................................................... 27

9.4 Dynamic Response to a Persistent Cost-push Shock: Committee ........................................ 28

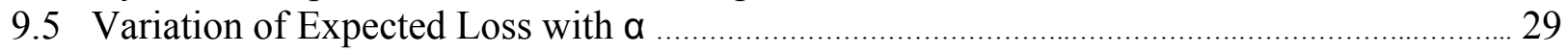

9.6 Variation of Expected Loss with $\alpha$ - McCallum and Nelson (2004) Calibration ............... 30

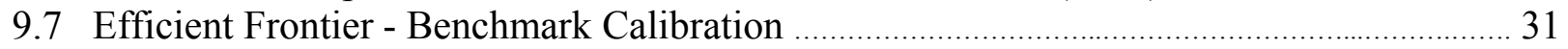

9.8 Efficient Frontier - McCallum and Nelson (2004) Calibration .......................................... 32 


\section{Introduction}

The responsibility for the conduct of monetary policy in many countries lies with a committee. Major central banks, most notably the Federal Reserve, the European Central Bank, the Bank of England, the Bank of Japan, and the Bank of Sweden operate under Monetary Policy Committees (MPCs). These MPCs consist of a small number of individuals who are assigned for a certain period of time and reach their decisions in a variety of manners. ${ }^{1}$ However, the literature on monetary policy has often focused on a single, infinitely-lived central banker. This paper proposes a model where members of the MPC have finite, overlapping tenures and studies the implications of departing from the standard institutional setup assumed in the previous literature.

I start by analyzing a two-member MPC in Section 3.1. I assume each member is in office for two periods, and in each period there are two MPC members in office. Furthermore, I assume each MPC member sits on the committee with an older MPC member in their first term and with a younger MPC member in their second term. Since there is an overlap between the tenures of different MPC members I refer to this model as a model of overlapping generations of MPC members. Each MPC member's loss function is defined over their two-period tenure and penalizes them for deviations of inflation and output gap from their respective targets. The setup is otherwise standard to the New Keynesian literature (see Clarida, Gali, and Gertler (1999), McCallum and Nelson (2004), and Woodford (2003), Ch.7). The inflation-output gap trade-off is governed by a Phillips curve which can be derived from a variety of price rigidity models, such as a staggered pricing model of Calvo (1983) or Taylor (1980) and a price adjustment cost model of Rotemberg (1982). ${ }^{2}$

I assume that each MPC member is able to commit to a path of future statecontingent policies. The overlapping structure of MPC member tenures will imply that the equilibrium outcome will be different from the optimal policy under commitment. ${ }^{3}$ A young MPC member would like to optimize in their first period and commit to a strong inflation response thereafter. On the other hand, an old MPC member has already made state-contingent plans in the first period of their tenure and thus does not want to reoptimize. This is the source of disagreement between the overlapping generations of MPC members. Put differently, an MPC member can commit to their own future policies but cannot influence the behavior of their successors. Therefore the incoming MPC members do not have access to a precommitment technology. Under rational expectations and without a precommitment technology, the incoming MPC members find it optimal to choose policy sequentially in their first period.

\footnotetext{
${ }^{1}$ See Blinder (1998) and Gerlach-Kristen (2008) for a discussion of different decision making procedures in MPCs.

${ }^{2}$ See Roberts (1995).

${ }^{3}$ See, for instance, Clarida, Gali, and Gertler (1999), and Woodford (2003), Ch.7.
} 
Further, I assume that differences between the choices of the old and the young MPC members are resolved through a utilitarian bargaining mechanism (Mas-Colell, Whinston, and Green (1995), Chapter 12). This implies that the old and the young MPC members maximize the sum of their objective functions. I will show that this solution coincides with averaging the desired inflation rates proposed by each MPC member.

In Section 3.3, I extend the analysis to a larger MPC in which a fixed proportion $(1-\alpha)$ of MPC members retire in each period and are replaced by young members. Therefore, in each period a proportion $\alpha$ of the MPC are old and the remaining $(1-\alpha)$ share are young. I refer to this process as churning and to $(1-\alpha)$ as the churning rate. Again, MPC members reach decisions under a utilitarian bargaining mechanism, but now the share of each group in the MPC determines their weight in the bargaining process. An MPC in which old policy members never retire is not different from a single infinitely-lived MPC member who possesses a commitment technology. On the other hand, an MPC in which churning is complete (that is when the entire committee is replaced by new members in each period) is equivalent to a single MPC member acting under discretion. ${ }^{4}$ Any churning rate in between these two extreme examples results in paths for inflation and output that are neither like those under discretionary monetary policy nor under full commitment but something in between. These intermediate results are similar to the concepts of quasi commitment suggested by Schaumburg and Tambalotti (2007), loose commitment by Debortoli and Nunes (2007) or imperfect credibility by Kara (2003). Whereas these studies assume an exogenous stochastic process that determines when and how often past promises are ignored, the present paper suggests an institutional reason that justifies imperfect credibility and imposes the frequency with which promises are broken.

The model implies that slower churning rates in MPC increase social welfare. This means that at any point in time the majority of MPC members should be old. The larger the proportion of old members in the MPC, the closer are monetary outcomes to optimal policy under commitment. The important question that arises is to what extent the institutional setup (in particular, the size of churning) influences changes in welfare. I show that this relation is quite sensitive to calibration. In particular, the results in Schaumburg and Tambalotti (2007), who find that small departures from discretionary monetary policy bridge most of the gap in terms of welfare between discretionary and commitment policy, do not hold in general. I find that under the benchmark calibration gains from commitment increase linearly with the proportion of old MPC members. This sensitivity to calibration is consistent with the results

\footnotetext{
${ }^{4}$ As Blinder (1998) points out, if all members of an MPC are identical it does not matter whether decisions are made by an individual or by a committee. What differentiates monetary outcomes under a committee vs. under an individual policy maker in this model is that MPC members start their tenures at different periods.
} 
in Debortoli and Nunes (2007), who also offer a model of loose commitment similar to that of Schaumburg and Tambalotti (2007) and apply their theoretical model to the determination of fiscal policy. When the government has access to a commitment technology, the optimal long-run capital tax rate is zero, a result common in the optimal taxation literature. In the absence of such a technology, the capital tax is positive: once capital has been accumulated the government has a temptation to tax it. Debortoli and Nunes (2007) find that when the probability of keeping promises is decreased from 1 to 0.75 , most variables move more than halfway toward discretionary outcomes.

\section{$1.1 \quad$ Related Literature}

This paper is related to a few strands in the literature. The most obvious is the literature on MPCs. ${ }^{5}$ As noted by Blinder (1998), some form of heterogeneity must distinguish the MPC members from each other for policy under an MPC to be different from outcomes under an individual policymaker. A number of papers assume differences in preferences, for instance, different weights assigned to the twin objectives of inflation and output stabilization (see Aksoy, De Grauwe, and Dewachter (2002), Hefeker (2003) and Sibert (2003)). Hahn and Gersbach (2001) consider differences in skill, and Gerlach-Kristen (2006) studies an MPC whose members have different information. To the best of my knowledge, no other paper analyzes MPCs where members have overlapping tenures.

The present paper does not aim to justify the existence of MPCs (for an example see Gerlach-Kristen (2006)); it rather takes the overlapping structure of an MPC as given. However, it has implications for how different decision-making procedures affect welfare. Gerlach-Kristen (2006) presents a model in which the MPC members receive different signals about the economy and studies the performance of different decision-making procedures in this economy. She concludes that setting the interest rate equal to the average of the rates favored by individual MPC members coincides with the optimal procedure if the committee members receive signals of equal quality. On the other hand, under a voting procedure the committee's choice of interest rate will be equal to the median of the interest rates proposed by the MPC members. Thus, averaging is favored over a voting procedure, under the condition that signal quality is the same for all the MPC members. In the setup proposed in this paper, the result of a voting procedure is trivial: if the majority of the MPC members are old, equilibrium under voting will be identical to the policy under commitment. On the other hand, if young members are in majority, the voting procedure will result in the discretionary policy. Therefore, voting could be superior or inferior to a utilitarian bargaining in my model.

\footnotetext{
${ }^{5}$ See Blinder (1998) for a general discussion of the literature on MPCs.
} 
This paper is also related to previous work on imperfect credibility or quasi commitment. Since the seminal work by Kydland and Prescott (1977) time consistency of a policy with or without a commitment technology is well understood. More recently, a literature has emerged which abandons the assumption that policy is either conducted under full commitment or under period-by-period optimization. These papers build models that can support a continuum of policies under varying degrees of commitment by the central bank.

Schaumburg and Tambalotti (2007) offer a model of quasi commitment by the central bank. In their model the monetary authority is assumed to formulate optimal commitment plans but is tempted to renege on them and succumbs to this temptation with a constant exogenous probability known to (and internalized by) the private sector. By varying this probability of reoptimization, the authors investigate the welfare effect of a marginal increase in credibility. The present model provides an example of an institutional setting which gives rise to this exogenous probability.

In a similar paper Kara (2003) analyzes an additional departure from perfect commitment. He uses the term imperfect commitment to refer to the possibility that the central bank will renege on its promises as is the case in Schaumburg and Tambalotti (2007). However, he allows the actual probability with which the central bank reoptimizes and the probability of reoptimization perceived by the public to be different. If the private sector expects the commitment not to last as long as actually intended by the central bank, the monetary authority is said to have imperfect credibility. Kara (2003) examines an optimizing monetary authority that has both imperfect commitment and imperfect credibility and shows that it will choose a less history dependent rule than in the case with perfect credibility.

Finally, a similar analysis of policy commitment is widely conducted in the fiscal policy literature, especially in the theory of optimal capital taxation. Judd (1985) shows that in a broad class of representative agent models the optimal tax on capital in a deterministic steady state is zero. He assumes that the government has access to a commitment technology. In the absence of a commitment technology, agents could enforce a given equilibrium using a trigger strategy. The public and the government follow a particular belief and action strategy, which is optimal and revert to the suboptimal, non-strategic equilibrium, should the other party deviate. This mechanism is used in Chari and Kehoe (1990). Kurozumi (2008) applies the mechanism suggested by Chari and Kehoe (1990) in a monetary policy context. These strategies rely on the assumption of an infinite horizon and will not be sustained in the model presented in this paper, in which the tenure of each MPC member is finite. In this paper, I assume that individual MPC members can commit to their own actions once they are in office without the need to revert to a trigger strategy. However, in my model MPC members cannot guarantee the actions of their successors or precommit to the policies 
they will enact when appointed, and thus, the resulting equilibrium will depart from the optimal commitment equilibrium.

Alternatively, Persson, Persson, and Svensson (2006) and Lucas and Stokey (1983), suggest a mechanism that makes the commitment solution time-consistent. Each government should leave its successor with a carefully chosen maturity of nominal and indexed debt for each contingent state of nature and at all maturities. This strategy recovers the optimal policy under commitment without access to such technology. Their solution requires a commitment to honor previous debt but it does not require a commitment about taxes. In the context of monetary policy this solution will not be operational since there are no state variables that could link two consecutive periods. ${ }^{6}$ In other words, there are no instruments that would allow an MPC member to affect the decisions of their successor. The new MPC member could reset inflation and output gap instantaneously and in effect reoptimize the problem.

The contribution of this paper is twofold. First, the model studies a departure from the standard New Keynesian framework assumptions, which brings the model closer to what we observe in reality. Specifically, I relax the assumption of a single infinitelylived MPC member (or an MPC whose objective function is infinitely long) and replace it with an overlapping structure for the MPC members as we observe in reality. Second, the model proposes a mechanism that gives rise to a monetary authority with imperfect commitment as opposed to imposing an exogenous probability with which previous promises are broken. ${ }^{7}$

The model allows welfare comparisons of different institutional structures. It suggests keeping the churning rate of the MPC low, whether decisions are made through a voting procedure or through (utilitarian) bargaining. In addition, if the churning rate is high, bargaining is preferred to voting. On the positive side the model suggests that welfare gains from commitment are sensitive to calibration. Under the benchmark calibration (Woodford 1999), welfare gains are close to linear in the churning rate of the MPC.

The remainder of this paper is organized as follows. Section 2 presents the theoretical model and derives the optimal monetary policy under commitment and discretion as benchmarks. Section 3 introduces the overlapping generations of the MPC members and discusses the solution to the model under utilitarian bargaining. It also extends the results to an $n$-member committee. Section 4 compares utilitarian bargaining with voting. Section 5 presents the model calibration and discusses the impulse responses of inflation and output gap under varying degrees of credibility. Section 6 concludes.

\footnotetext{
${ }^{6}$ This is inherent to the monetary policy problem. Note that both $x_{t}$ and $\pi_{t}$ are control variables, and not pre-determined by period $t-1$ decisions.

${ }^{7}$ See Schaumburg and Tambalotti (2007), Debortoli and Nunes (2007) and Kara (2003).
} 


\section{Optimal Monetary Policy: The New Keynesian Framework}

This section briefly reviews the canonical New Keynesian monetary policy model (see, for instance, Clarida, Gali, and Gertler (1999) and Woodford (1999)) and presents the solution under discretion and perfect commitment as benchmarks.

\subsection{Optimal Monetary Policy and Stabilization Bias}

The representative household maximizes utility in an economy with monopolistically competitive firms and some form of nominal rigidity. Consider an economy with a continuum of infinitely-lived private agents and a monetary policymaker. The private agents produce and consume a continuum of differentiated, imperfectly substitutable goods. The agents price their goods in an environment of monopolistic competition and in the presence of nominal rigidities of the form described by Calvo (1983). The supply side of the economy is obtained by log-linearizing the first-order condition of the firm's profit maximization problem. This gives rise to an equation often referred to as the New Keynesian Phillips Curve (NKPC) which takes the following form:

$$
\begin{gathered}
\pi_{t}=\beta E_{t} \pi_{t+1}+k x_{t}+v_{t} \\
v_{t}=\rho v_{t-1}+\epsilon_{t}
\end{gathered}
$$

where $x_{t}$ is the output gap (or the deviation of output from its natural level), $\pi_{t}$ is the average price level inflation from time $t-1$ to time $t$, and $v_{t}$ is a cost-push shock representing a variety of supply shocks in the economy. $v_{t}$ is assumed to follow an $\operatorname{AR}(1)$ process with an autoregressive coefficient $\rho$ and is subject to innovations $\epsilon_{t}$ with the standard deviation $\sigma_{\epsilon} . \beta$ is the subjective discount factor of the representative consumer, and $k$ is a constant and a function of the structural parameters of the model. It is clear from the NKPC (2.1) that inflation is a forward-looking variable and depends positively on future expectations about inflation and the current output gap.

The demand side of the economy is described by a dynamic IS equation, which is simply a log-linear version of the Euler equation of the representative consumer

$$
x_{t}=E_{t} x_{t+1}-\sigma\left(i_{t}-E_{t} \pi_{t+1}-r_{t}^{n}\right)
$$

where $i_{t}$ is the nominal interest rate controlled by the central bank and $r_{t}^{n}$ is the natural (real) rate of interest. The natural interest rate is the rate that would prevail in an equilibrium with flexible prices. The parameter $\sigma>0$ is the intertemporal elasticity of substitution in consumption. 
The monetary authority minimizes a quadratic objective function subject to the NKPC (2.1) and the IS equation (2.3). As shown in Woodford (2003), Chapter 6, and Erceg and Levin (2006), this loss function can be obtained as a second-order approximation of the representative household's utility function with Calvo (1983) or Taylor (1980) style staggered pricing of monopolistically competitive firms. ${ }^{8}$ The period objective function depends on the variance of the output gap, $x_{t}^{2}$, and the variance of inflation, $\pi_{t}^{2}$, in the economy. Specifically, the monetary authority minimizes:

$$
L=E_{0} \sum_{t=0}^{\infty} \beta^{t}\left[\pi_{t}^{2}+\lambda x_{t}^{2}\right]
$$

Note that in this specification the monetary authority's inflation and output gap targets are both assumed to be zero. Targeting the natural rate of output eliminates the traditional inflation bias à la Barro and Gordon (1983). The monetary authority will not attempt to push the economy beyond its potential through inflation surprises. For example, the monopolistic competition distortions could be removed and the efficient level of output restored using subsidies, eliminating the need for monetary policy to target an output level higher than the natural rate. Nevertheless, as argued extensively in Clarida, Gali, and Gertler (1999) and Woodford (1999), a monetary authority that can commit to a policy will still deliver a better outcome than under discretion since commitment offers an extra policy instrument. This additional instrument is the monetary authority's ability to influence expectations through promises about future policies. By committing to future policies a monetary authority can internalize the effect of its decisions on expectations and thus gain an extra policy tool.

\subsection{Optimal Response under Discretion}

In the absence of a commitment technology, the monetary authority takes agents' expectations as given, which will result in sub-optimal outcomes. This inefficiency is often referred to as the stabilization bias. In effect the monetary authority reoptimizes the objective function in every period, taking the expectations about future values of inflation as given. Thus, the dynamic optimization problem above breaks into an infinite number of contemporaneous optimization problems, or one-shot games. This is what is referred to as the discretionary outcome. The problem therefore simplifies to minimizing

$$
L_{t}=\left(\pi_{t}^{2}+\lambda x_{t}^{2}\right)
$$

subject to (2.1) and (2.3). Note that since $i_{t}$ does not appear in the objective function, the constraint (2.3) can be ignored. We can obtain the optimal solutions for $\pi_{t}$ and

\footnotetext{
${ }^{8}$ This result relies on the assumption that the monetary authority (or the MPC) has a loss function spanning an infinite horizon. This condition is not satisfied in the overlapping generations model presented, where each MPC member's loss function spans only a finite period. See Debortoli and Nunes (2007).
} 
$x_{t}$ by minimizing the monetary authority's loss function, subject only to the NKPC (2.1), and then recover the optimal path for $i_{t}$ using the IS relationship.

The first-order condition of this optimization problem is

$$
\pi_{t}+\frac{\lambda}{k} x_{t}=0
$$

Combining (2.5) with the NKPC (2.1), we obtain the following expressions for $\pi_{t}$ and $x_{t}$ :

$$
\begin{aligned}
& \pi_{t}=\frac{\lambda}{\kappa^{2}+\lambda(1-\beta \rho)} v_{t} \\
& x_{t}=-\frac{k}{\kappa^{2}+\lambda(1-\beta \rho)} v_{t}
\end{aligned}
$$

Note that both inflation and output gap are functions of the current period cost-push shock. This implies that the monetary authority brings inflation back to its zero level target immediately. The impulse responses of inflation and output gap to a one standard deviation cost-push shock are shown in figure (9.1).

\subsection{Optimal Response under Commitment}

When the monetary authority has access to a commitment technology, it has the ability to influence expectations by committing to a rule that binds policy behavior in the future. Therefore, the problem is no longer a static optimization. The Lagrangian $\mathcal{L}_{c}$ can be written as

$$
\mathcal{L}_{c}=E_{0} \sum_{t=0}^{\infty} \beta^{t}\left[\pi_{t}^{2}+\lambda x_{t}^{2}+2 \varphi_{t}\left(\pi_{t}-\beta E_{t} \pi_{t+1}-k x_{t}-v_{t}\right)\right]
$$

where $\varphi_{t}$ is the Lagrange multiplier on constraint (2.1) in period $t \geq 0$. The first-order condition for the optimal policy is then obtained by differentiating (2.8) with respect to $\pi_{t}$ and $x_{t}$ :

$$
\begin{gathered}
\pi_{t}-\varphi_{t}+\varphi_{t-1}=0 \text { and } \\
\lambda x_{t}+k \varphi_{t}=0 \quad \forall t \geq 0
\end{gathered}
$$

together with the initial condition that $\varphi_{-1}=0$, which indicates no previous commitment in period zero. Eliminating the Lagrange multipliers yields an inflation rate rule that implements the optimal policy

$$
\begin{gathered}
\pi_{0}=-\frac{\lambda}{k} x_{0} \text { and } \\
\pi_{t}+\frac{\lambda}{k}\left[x_{t}-x_{t-1}\right]=0 \quad \forall t>0
\end{gathered}
$$


Woodford (1999) argues that the optimal policy under commitment lacks continuity in this form. This means that policy at time zero is different from policy at all other periods, which makes $t=0$ arbitrarily special. He thus proposes its variant from a timeless perspective, which requires the equilibrium to be optimal in all periods. This condition implies that the commitment policy is also implemented at time zero. The optimal policy from a timeless perspective is implemented by an inflation rate rule of the following form: ${ }^{9}$

$$
\pi_{t}+\frac{\lambda}{k}\left[x_{t}-x_{t-1}\right]=0 \quad \forall t \geq 0
$$

The inflation rate rule (2.11), together with the NKPC (2.1), implies the following second-order difference equation in $x_{t}$ :

$$
x_{t+1}-\left(\frac{\beta+1+k^{2} / \lambda}{\beta}\right) x_{t}+\frac{1}{\beta} x_{t-1}=\frac{k}{\beta \lambda} v_{t}
$$

The stationary solution to this difference equation is:

$$
x_{t}=\mu_{1}^{c} x_{t-1}-\frac{k}{\lambda \beta\left[\mu_{2}^{c}-\rho\right]} v_{t}
$$

where $\mu_{1}^{c}<1$ and $\mu_{2}^{c}>1$ are the roots to the characteristic equation below:

$$
\mu^{2}-\left(\frac{\beta+1+k^{2} / \lambda}{\beta}\right) \mu+\frac{1}{\beta}=0
$$

The unique solution for $\pi_{t}$ is obtained by combining the solution for $x_{t},(2.13)$, and the first-order condition, (2.11):

$$
\pi_{t}=\frac{\lambda}{k}\left(1-\mu_{1}^{c}\right) x_{t-1}+\frac{1}{\beta\left[\mu_{2}^{c}-\rho\right]} v_{t}
$$

\section{Overlapping Generations of MPC Members}

This section introduces an MPC with overlapping generations of members. First, it analyzes the structure of a two member MPC. It defines the bargaining mechanism and derives the equilibrium path of inflation, output gap, and interest rates. It then generalizes the solution to an $n$-member MPC and derives the equilibrium policy.

\footnotetext{
${ }^{9}$ Note the difference between (2.11) and (2.9). Under a timeless perspective, optimal commitment policy applies to time zero as well.
} 


\subsection{A Two-Member MPC}

Consider the following setup. Monetary policy is set by an MPC which comprises two-members in each period. Each MPC member is in office for two periods. The first period of their tenure overlaps with the second period of their predecessor's term in office. In the second period of their term, an MPC member shares office with their successor. So, during each period the terms of two generations of MPC members overlap. In this paper I refer to an MPC member as young while serving their first term and as old while serving their second (or any subsequent) terms.

The objective function of each MPC member only spans across their tenure while in office. Specifically, consider the two MPC members who share an office in period $t$. I label the loss function of each MPC member by the date at which they begin their term in office. The objective function of an MPC member who begins their term at time $t-1$ is

$$
L_{t-1,0}=-\beta^{t-1} E_{0}\left[\left(\pi_{t-1}^{2}+\lambda x_{t-1}^{2}\right)+\beta\left(\pi_{t}^{2}+\lambda x_{t}^{2}\right)\right]
$$

where $L_{t-1,0}$ denotes the time zero expectation of the objective function of an MPC member whose term begins at time $t-1$. Similarly, the time zero expectation of the objective function of an MPC member whose term begins at time $t$ is as follows.

$$
L_{t, 0}=-\beta^{t} E_{0}\left[\left(\pi_{t}^{2}+\lambda x_{t}^{2}\right)+\beta\left(\pi_{t+1}^{2}+\lambda x_{t+1}^{2}\right)\right]
$$

The old MPC member would like to minimize $L_{t-1,0}$ subject to the NKPC in periods $t-1$ and $t$. That is,

$$
\begin{aligned}
\pi_{t-1} & =k x_{t-1}+\beta E_{t-1} \pi_{t}+v_{t-1} \text { and } \\
\pi_{t} & =k x_{t}+\beta E_{t} \pi_{t+1}+v_{t}
\end{aligned}
$$

whereas the young MPC member would like to minimize $L_{t, 0}$ subject to

$$
\begin{aligned}
\pi_{t} & =k x_{t}+\beta E_{t} \pi_{t+1}+v_{t} \text { and } \\
\pi_{t+1} & =k x_{t+1}+\beta E_{t+1} \pi_{t+2}+v_{t+1}
\end{aligned}
$$

One can impose the constraints each MPC member faces into their objective functions, given that these constraints should always be binding. This means that

$$
L_{s, 0}=-\beta^{s} E_{0}\left\{\begin{array}{c}
{\left[\pi_{s}^{2}+\lambda\left(\frac{\pi_{s}-\beta E_{s} \pi_{s+1}-u_{s}}{\kappa}\right)^{2}\right]} \\
+\beta E_{s}\left[\pi_{s+1}^{2}+\lambda\left(\frac{\pi_{s+1}-\beta E_{s+1} \pi_{s+2}-u_{s+1}}{k}\right)^{2}\right]
\end{array}\right\}
$$

where $L_{s, 0}$ defines the objective function of the lifetime maximization problem of an MPC member whose career begins at time $s . L_{s, 0}$ already takes into account the constraints that each MPC member faces in their lifetime. The two MPC members 
in office at any point in time decide what the inflation and output gap in that period should be through a bargaining process. ${ }^{10}$

The source of disagreement between the old and the young MPC members in office at any given period is their uneven access to a commitment technology. I have assumed that each MPC member can only commit to their own future policies. Therefore, they have access to a commitment technology while in office, but not to a precommitment technology that allows them to credibly commit to a state-contingent policy in the first period of their tenure. This assumption may be justified in the real world in that policymakers are unknown before they are appointed and there is a larger uncertainty about their future policies. However, once they occupy office and announce their future plans, the uncertainty is reduced to a great extent.

Take the two MPC members in office at time $t$. In the setup proposed above the lack of a precommitment technology for the incoming MPC member leads them to choose policy sequentially in their first period. The young MPC member would maximize (3.2) subject to (3.5) and (3.6) taking private agents' expectations about $\pi_{t}$ as given. On the other hand, the old MPC member maximizes (3.1) subject to (3.3) and (3.4). Since this policymaker has already served in $t-1$, they have had the ability to commit to their time $t$ policy and therefore influence $E_{t-1} \pi_{t}$. The ability to influence expectations offers the old MPC member a better trade-off between inflation and output gap. This is the source of disagreement between the two MPC members that needs to be resolved through bargaining.

Next, I explore the bargaining process and its equilibrium solution to the monetary design problem.

\subsection{The Bargaining Process}

The two MPC members in office at any time period $t$ decide what the inflation and output gap at that period will be through a bargaining process. This can be thought of as a time zero bargaining. In other words, all future MPC members meet at time zero and agree on a state-contingent plan. I make two important assumptions for the following analysis. First, only the MPC members in office at time $t$ can decide on the monetary outcomes of period $t$. This is a crucial assumption since all MPC members taking office from time $t$ onwards affect variables at time $t$ by influencing the expectations of agents about future. Therefore, potentially all MPC members could enter into a grand bargain and decide on a state-contingent plan for the paths of inflation and output gap. The optimal outcome under this scenario would be equivalent to the commitment solution. By limiting the bargaining process to the two incumbents at each period, I rule out this grand bargain.

\footnotetext{
${ }^{10} \mathrm{As}$ is customary in such problems, we assume that the monetary authority decides the inflation level desired and the corresponding $i_{t}$ is uniquely determined from the IS equation.
} 
The second underlying assumption is that I analyze the solution from a timeless perspective (Woodford (1999)). Specifically, I assume that the time periods in the analysis are sufficiently far away from time zero that the effect of the initial period can be neglected. Put differently, I assume that the economy is operating far enough from the starting point that the initial conditions do not matter. Next, I analyze the bargaining mechanism and its equilibrium solution to the monetary policy design problem.

\subsubsection{The Bargaining Problem}

Mas-Colell, Whinston, and Green (1995) define a bargaining problem among $I$ agents by its two elements: a utility possibility set $U \subset \mathbb{R}^{I}$ and a threat point, or status quo point $u^{*} \in U$. The set $U$ represents the allocations of utility that can be settled on if there is cooperation among the agents. The point $u^{*}$ is the outcome that will occur if there is a breakdown of cooperation. Cooperation requires the unanimous participation of all agents and thus in equilibrium will imply that : $U \geq u^{*} \imath$ where $\imath$ is a unity vector of length $I$.

Definition $1 A$ bargaining solution is a rule that assigns a solution vector $f\left(U, u^{*}\right) \in$ $U$ to every bargaining problem $\left(U, u^{*}\right)$.

In this particular problem $U_{t}=\left(L_{t-1}, L_{t}\right)^{\prime}$. In other words, the bargaining possibility set at time $t$ comprises the objective functions of the young and the old MPC members occupying office at time $t$.

Let the status quo point be $u^{*}=(-1,-1) .{ }^{11}$ The negative value for the status quo may be interpreted as the social costs of indecision or irreconcilable differences within the monetary authority and the ensuing public embarrassment. Note that the objective functions of both participants are always weakly positive, and therefore abandoning the bargaining process is never optimal for either party.

\subsubsection{The Utilitarian Solution and the Stationary Equilibrium}

In this paper I will consider a particular bargaining mechanism, namely the utilitarian solution. Define the utilitarian solution $f_{t}^{*}(U)$ such that it maximizes $\sum u_{i}$ on $U$. Given that $U$ is convex, the solution is uniquely defined. I focus on this bargaining solution for two reasons. First, the additive property of the problem makes the maximization tractable. The second reason is more conceptual. In an infinite horizon context, an agent minimizes a weighted average of the losses in all periods. The utilitarian solution

\footnotetext{
${ }^{11}$ The utilitarian solution considered here satisfies the property of independence of utility origins (IUO). This means that the bargaining solution does not depend on absolute scales of utility. Therefore, our choice of $u^{*}$ does not matter, and in fact, we can suppress the term $u^{*}$ in the definition of $f$.
} 
to the bargaining problem is similar in that it proposes to minimize a weighted average of the losses accrued to each party (or all parties, in the case of a committee).

In the case of an MPC which comprises two members, $f_{t}(U)$ maximizes the sum of the two utility payoffs from each party. Therefore, the two MPC members choose $\pi_{t}$ and $x_{t}$ to find:

$$
f_{t}^{*}(U)=\max _{\pi_{t}, x_{t}}\left[L_{t-1,0}+L_{t, 0}\right]
$$

where $L_{t-1}$ and $L_{t}$ are defined as in (3.7).

The first-order condition of the maximization problem with respect to $\pi_{t}$ is:

$$
\left[\pi_{t}+\frac{\lambda}{k} x_{t}-\frac{\lambda}{k} x_{t-1}\right]+\left[\pi_{t}+\frac{\lambda}{k} x_{t}\right]=0
$$

Note that the first-order condition (3.9) is an average of the two first-order conditions under commitment and discretion (cf. first-order conditions (2.5) and (2.11)). Substituting the first-order condition (3.9) into the NKPC (2.1) yields a second-order difference equation for $x_{t}$ :

$$
x_{t+1}-\left(\frac{\beta / 2+1+k^{2} / \lambda}{\beta}\right) x_{t}+\frac{1}{2 \beta} x_{t-1}=\frac{k}{\beta \lambda} v_{t}
$$

Its characteristic polynomial is

$$
\mu^{2}-\left(\frac{\beta / 2+1+k^{2} / \lambda}{\beta}\right) \mu+\frac{1}{2 \beta}=0
$$

and has roots $\mu_{1}$ and $\mu_{2}$ inside and outside the unit circle respectively. The corresponding solutions for $x_{t}$ and $\pi_{t}$ are:

$$
\begin{aligned}
x_{t} & =\mu_{1} x_{t-1}-\frac{k}{\lambda \beta\left[\mu_{2}-\rho\right]} v_{t} \\
\pi_{t} & =\frac{\lambda}{k}\left(1-\mu_{1}\right) x_{t-1}+\frac{1}{\beta\left[\mu_{2}-\rho\right]} v_{t}
\end{aligned}
$$

Comparing these roots with $\mu_{1}^{c}$ and $\mu_{2}^{c}$ from (2.13), one can verify that $\mu_{1}<\mu_{1}^{c}$ and $\mu_{2}<\mu_{2}^{c}$. This implies that the equilibrium response of the output gap to a cost-push shock is less persistent compared to optimal policy under commitment, and closer to the response under discretion. The equilibrium response of inflation, output gap and interest rates under a two member committee are displayed in figure (9.2) with a dashed-plus line. We can see that the responses of all three variables are roughly halfway between the responses under commitment and discretion. The initial response of inflation and output gap are smaller than that under discretion but larger compared to optimal policy under commitment. As argued above, all three variables show less persistence compared to the policy under commitment. 


\section{3 n-Member Committee}

The results of the previous section can be extended to a more general setting. In this section, I relax two assumptions about the setup in Section 3.1. First, the MPC is composed of $n \geq 2$ members. Second, MPC members serve a $T$-period term $(T \geq 2)$. Here, an MPC member is considered young if and only if they are serving their first term. Note that it is only the first term that is special in the optimal policy under commitment. If policy were timeless, as suggested by Woodford (1999), or the tenure of an MPC member were long enough for the effect of time zero to be ignored, then nothing would distinguish different MPC members from each other, regardless of when they started their term. However, when tenures are finite, the incoming MPC members find it optimal to implement the discretionary policy in their first term. This is the source of disagreement between the young and the old policymakers.

Assume that at any period $t$, the MPC is made up of $n$ members. Further assume that in each period a portion $n_{y}$ of the MPC members retire and are replaced by young ones. Therefore, at any period $t$ the MPC is composed of $n_{y}$ young members and $n_{o}=n-n_{y}$ old members. Note that the number of incoming and outgoing members should be equal for the size of the committee to remain constant. I refer to $\frac{n_{o}}{n}=\alpha$ and define the churning rate to be $1-\alpha$. A constant churning rate $1-\alpha$ and a constant committee size requires that $n_{y} \mathrm{MPC}$ members retire in each period and are replaced by young ones. All the members of the MPC at time $t$ should retire by $t+T$. Therefore, it must be the case that $n_{y}=n / T$. Moreover, not all of the old MPC members begin their careers in the same period. The only distinction we need to make is between those members whose terms start at time $t$ and those members who have started their terms earlier. The bargaining solution will maximize the sum of all MPC members' utilities. Again, denote the loss function of an MPC member by a subscript referring to the date their tenures begin. Thus, $L_{j, 0}$ denotes the time zero expectation of the loss function of an MPC member whose term begins at time $j$. For determining monetary policy at time $t$, all MPC members whose terms began from $t-T+1$ to MPC members beginning their tenure at $t$ enter the bargaining process. The utilitarian solution to this problem is defined as:

$$
f_{t}^{*}(U)=\max _{\pi_{t}, x_{t}} \sum_{i=1}^{T-1} \omega_{i} L_{t-i, 0}+n_{y} L_{t, 0}
$$

where $L_{s, 0}$ is the time zero expectation of the loss function of an MPC member whose term began at time $s$ and is defined as

$$
L_{s, 0}=-\beta^{s} E_{0} \sum_{i=0}^{T-1}\left[\pi_{s+i}^{2}+\lambda\left(\frac{\pi_{s+i}-\beta E_{s} \pi_{s+i+1}-u_{s+i}}{\kappa}\right)^{2}\right]
$$

and $\omega_{i}$ are the number of old MPC members whose terms begin at time $t-i$. Note 
that $\sum \omega_{i}=n_{o}$. Differentiating equation (3.13) with respect to $\pi_{t}$ yields the following first-order condition:

$$
n_{o}\left[\pi_{t}+\frac{\lambda}{k} x_{t}-\frac{\lambda}{k} x_{t-1}\right]+n_{y}\left[\pi_{t}+\frac{\lambda}{k} x_{t}\right]=0
$$

Equation (3.14) shows that the first-order condition under a utilitarian bargaining solution is a weighted average of the first-order conditions of the old and the young MPC members. Rewrite equation (3.14) as

$$
\alpha\left[\pi_{t}+\frac{\lambda}{k} x_{t}-\frac{\lambda}{k} x_{t-1}\right]+(1-\alpha)\left[\pi_{t}+\frac{\lambda}{k} x_{t}\right]=0
$$

where $(1-\alpha)=\frac{n_{y}}{n}$, or the churning rate. Combining first-order condition (3.14) and substituting it into the NKPC (2.1) yields a second-order difference equation for $x_{t}$ :

$$
x_{t+1}-\left(\frac{\alpha \beta+1+k^{2} / \lambda}{\beta}\right) x_{t}+\frac{\alpha}{\beta} x_{t-1}=\frac{k}{\beta \lambda} v_{t}
$$

This difference equation is stable with constant coefficients if and only if the ratio $\alpha$ of old MPC members to the total is constant at all times. ${ }^{12}$ The characteristic polynomial of this difference equation is

$$
\mu^{2}-\left(\frac{\alpha \beta+1+k^{2} / \lambda}{\beta}\right) \mu+\frac{\alpha}{\beta}=0
$$

and has roots $\mu_{1}^{\alpha}$ and $\mu_{2}^{\alpha}$ inside and outside the unit circle respectively. The solution for $x_{t}$ is:

$$
x_{t}=\mu_{1}^{\alpha} x_{t-1}-\frac{k}{\lambda \beta\left[\mu_{2}^{\alpha}-\rho\right]} v_{t}
$$

It can be shown that $\frac{\partial \mu_{1}}{\partial \alpha}>0 \forall \alpha \in[0,1]$. Furthermore, note that when $\alpha=1$, the solution coincides with that under commitment and when $\alpha=0$ the solution coincides with period-by-period optimization. The immediate conclusion is that the lower the churning rate (higher $\alpha$ ), the closer the outcomes will be to optimal policy under commitment.

This conclusion can be cast in terms of the duration of the MPC members' service as well. Note that the churning rate is defined as $1-\alpha=\frac{n_{y}}{n}=\frac{1}{T}$. As $T$ increases toward infinity, $\alpha$ increases toward 1 . This is reasonable; we would expect that the longer the duration of an MPC member's term in office, the closer the solution would be to that under full commitment. In the limit, if policy members never retire ( $T \rightarrow \infty$ or $\alpha=1)$, then the outcomes would be identical to those under commitment. On the other hand, if $T=1$ (or $\alpha=0$ ), each MPC member will be in office for one term only, clearly delivering the solution under discretion.

\footnotetext{
${ }^{12}$ This condition is equivalent to a constant churning rate.
} 


\section{Utilitarian Bargaining vs. Vot- ing}

Blinder (1998) classifies MPCs into individualistic vs. collegial. In individualistic committees decisions are reached through voting: positions are offered and debated and once all committee members put forth their case, they vote. On the other hand, in a collegial committee a consensus is built and recalcitrant members are persuaded to go along (usually by the chair person).

The model presented here could be interpreted as a collegial committee whereby a compromise solution is reached. Inflation is chosen as the weighted average of inflation levels favored by all MPC members. What would be the result if decisions were made through voting instead? Alternatively, how would an overlapping generations structure for MPC members affect the monetary outcomes if the MPC was more "individualistic" as opposed to "collegial" to use Blinder's terms?

Gerlach-Kristen (2006) compares decision-making procedures in a model where there is uncertainty about potential output. She compares an "averaging" procedure, where the interest rate is set equal to the mean of the rates favored by the individual MPC members with a voting procedure, which implements the median of these rates. She concludes that averaging coincides with the optimal procedure if the committee members are "equally skilled" in the sense that the signals they receive in the economy are of equal quality; however, voting can lead to better decisions than averaging if abilities vary between policymakers.

In the model presented in this paper, a voting procedure has a trivial outcome. If the majority of the committee members are old, the voting outcome will be the same as policy under commitment. Otherwise, voting will result in discretionary monetary policy. Thus, whether voting improves welfare compared to bargaining depends on the composition of the committee. What is clear is that under both procedures a low churning rate is preferred. However, as I will show numerically in the next section, the gains from low churning rates are continuous under bargaining whereas they are discrete under voting. These results suggest that if the churning rate in the MPC is low, voting is preferred to bargaining since voting will recover the outcome under commitment but bargaining will not. On the other hand, if the churning rate is high, bargaining is the preferred decision-making procedure. ${ }^{13}$

\footnotetext{
${ }^{13}$ Note that the bargaining outcome is strictly preferred to the discretionary policy as long as the churning rate is less than $100 \%$.
} 


\section{Calibration and Simulation Re- sults}

The benchmark calibration follows Woodford (1999) and is summarized in table (8.1). The model is assumed to refer to quarterly variables, with interest rates and inflation measured as annualized percentages. All parameter values are standard, with the exception of the relative weight on the output gap in the monetary authority's loss function, which is relatively low. ${ }^{14} \mathrm{I}$ also report the results for values of $\lambda$ more commonly found in the optimal monetary policy literature.

One measure of the loss to the society is the unconditional expectation of expression (2.4). ${ }^{15}$ I choose this as my welfare measure. I follow Schaumburg and Tambalotti (2007) and report the changes in welfare associated with different levels of credibility as a fraction of the total difference in welfare between discretion and commitment. ${ }^{16}$

Table (8.1) also compares the benchmark calibration with another set of parameters commonly used in the literature, used by McCallum and Nelson (2004). These authors suggest that the actual value of $\kappa$ probably lies between 0.01 and 0.1 , which is consistent with the estimates in Gali and Gertler (1999). The value of $\lambda$ which is related to the monetary authority preferences is more subjective. The range suggested by McCallum and Nelson (2004) includes the benchmark parameter.

\subsection{Impulse Responses to Independent Shocks}

Impulses are normalized to produce an annualized one percentage point increase in inflation on impact for given expectations. Given the forward-looking nature of the model, the actual increase in inflation is a function of the forecasted response of the equilibrium policy to the shock.

I assume that the economy starts in the steady state with zero inflation and no output gap. Figure (9.1) shows the path of inflation, output gap and interest rate under commitment and discretion. With the benchmark calibration, this replicates the results in Woodford (1999). Under discretion the monetary authority moves its instrument with the shock, returning the economy to the steady state as soon as the effects of the shock have faded. Given an i.i.d. impulse, this implies that the economy is driven into a sharp recession, accompanied by high inflation, but only for one period.

\footnotetext{
${ }^{14}$ This low value is derived from a micro-founded model which approximates the loss function as a second-order expansion of the utility function of the representative consumer. It is therefore consistent with the rest of the structural parameters.

${ }^{15}$ This is the metric chosen by King and Wolman (1999), Rotemberg and Woodford (1999), Rudebusch and Svensson (1999), and Walsh (2003).

${ }^{16}$ This method eliminates the need to specify the standard deviation of the cost-push shock.
} 
This is the policy that each young MPC member would like to choose in any period following the period of the shock.

Under commitment, the monetary authority exploits the possibility of influencing inflation expectations in its favor in the period of the shock by promising a protracted mild recession, accompanied by deflation. This can be accomplished with a relatively limited movement in the interest rate compared to the discretion case. ${ }^{17}$ It is clear why without a commitment technology this path for the interest rates is time inconsistent: the monetary authority would want to return to zero inflation and output gap as soon as the shock has disappeared. Note that in the absence of new shocks and inflation bias, the steady state values of the endogenous variables under discretion are consistent with those under optimal policy with commitment.

These two extreme results are also obtained with an MPC when monetary policy is set by voting among MPC members. As noted in Section 4, if the level of inflation is decided upon by a simple majority vote, then the paths of inflation, output gap and interest rates will be those under optimal policy with commitment when a majority of MPC members are old. On the other hand, when the majority of MPC members are young the equilibrium paths of variables of interest will be those under discretionary monetary policy.

Now consider the response of variables when monetary policy is set by an MPC. As argued in Section 3.3, this is equivalent to choosing an inflation level equal to the average of inflation levels favored by all MPC members. First consider the impulse response of the two-member committee studied in Section 3.1. Figure (9.2) presents these impulse responses (with a dashed-plus line). The paths of inflation, output gap, and interest rates under a two member committee are the same as those under a committee of any size with $\alpha=1 / 2$.

Note that the inflation response is roughly halfway between the response under commitment and discretion. This is unlike the results in Schaumburg and Tambalotti (2007), who conclude that relatively low levels of credibility are enough to produce qualitative responses of the economy very close to the ones obtained under commitment. Furthermore, the contraction required to bring back inflation to the steady state level is also halfway between that under discretion and commitment. Figure (9.2) also shows the monetary outcomes under a committee with three-quarters of its members being old. As we can see, the results are closer to the response under commitment. Very roughly, the responses of all variables are three-quarters of the way between discretionary and commitment response. I will quantify this more accurately in Section 6.

\footnotetext{
${ }^{17}$ We are assuming that there are no shocks to the natural interest rate.
} 
The response of the interest rates is similar. The optimal response to a positive cost-push shock is raising nominal interest rates. Under discretion, and when shocks are i.i.d., interest rates are raised heavily in the period of the shock but are brought back to their steady state value immediately after. Under commitment the initial rise in interest rates is much lower but the return to the steady state is very persistent. These two patterns are reflected in the response of interest rates under a committee. Under a two-member committee, or when $\alpha=1 / 2$, the initial hike in interest rates is roughly halfway between the discretionary and commitment responses. When $\alpha=$ $3 / 4$, the response is much closer to that under commitment.

\subsection{Impulse Responses to Persistent Shocks}

This section analyzes the response of the economy to a persistent shock $(\rho=0.80)$ (see figure (9.3)). It is apparent that the paths of variables under discretion and commitment are much closer to each other in the presence of such a shock. This is because the exogenous persistence of the shock causes a persistence in inflation and output gap responses that is desirable under commitment.

The initial rise in inflation and fall in output gap is much higher under a persistent shock compared to an i.i.d. shock. This is because of the forward-looking nature of the model. Although the initial shock is just as large as the one studied in the i.i.d. case, the prolonged cost-push shock implies a much higher cost in terms of output gap and a higher initial inflation. Figure (9.4) shows the response of these variables for a committee with $\alpha=0.5$ (dashed-plus line) and $\alpha=0.75$ (dashed-cross line) proportion of old members. The shape of all inflation responses are similar, with initial inflation hike being the highest under discretionary monetary policy. Furthermore, the paths of inflation with $\alpha=0.5$ and $\alpha=0.75$ are distributed quite evenly between the paths of inflation under commitment and discretion.

The path of the output gap shows a different pattern. Under discretion the response to a cost-push shock is always proportional to the current period output gap. Since the shock is monotonically decreasing in size, the output gap also increases monotonically toward its steady state. However, under commitment (and to a lesser degree under committees with $\alpha=0.5$ and $\alpha=0.75)$ there is some persistence in the equilibrium response of output gap to a cost-push shock. This means that the response to a persistent shock becomes hump-shaped, and the recession worsens before it gets better. The same non-monotonicity is reflected in the response of interest rates. In reality, the monetary authority would control interest rates and thus the hump-shaped pattern in interest rates would also be reflected in the output gap. ${ }^{18}$

\footnotetext{
${ }^{18}$ Since we have assumed away demand shocks, setting inflation or interest rate as monetary targets are equivalent.
} 


\section{Welfare Analysis}

An important question is the extent to which the institutional setup of an MPC influences the level of welfare. Schaumburg and Tambalotti (2007) answer this question in the context of their quasi commitment technology and conclude that only small deviations from discretion are needed in order to obtain welfare levels very close to optimal policy under commitment. I analyze the same question by looking at the changes in the society's welfare measure when the proportion of the old members in an MPC moves away from $\alpha=1$ (equivalent to policy under commitment) to $\alpha=0$ (equivalent to policy under discretion). The loss to the society is calculated as the unconditional expectation of variances in inflation and output gap as in (2.4). The variation of this loss function with $\alpha$ is demonstrated in figure (9.5). One can see that unlike the conclusion reached by Schaumburg and Tambalotti (2007), in this model, and under the benchmark calibration, the gains from commitment are close to linear in $\alpha$, or the degree of commitment.

It turns out that this linearity is specific to this calibration. Consider the alternative calibration suggested by McCallum and Nelson (2004) in table (8.1). Specifically, assume that $\lambda=0.1$ and $k=0.01$. As figure (9.6) shows, the variations in the loss function become a convex function of $\alpha$. In other words, the committee must be much closer to an old member majority before most benefits from commitment are obtained. This finding is consistent with the results reported by Debortoli and Nunes (2007), albeit in a monetary policy context. In the fiscal policy application they analyze, they find that a small departure from full commitment moves most variables substantially toward discretion.

Another metric for measuring the effect of varying $\alpha$ is to plot the volatility of output gap against inflation volatility associated with the optimal policy for different levels of $\alpha$. Figure (9.7) shows the efficient frontier under the benchmark calibration. Moving away from fully discretionary monetary policy (in which case all MPC members begin their terms simultaneously) will reduce both the standard deviation of output gap and inflation. Beyond a certain threshold value for $\alpha$, decreases in inflation volatility require higher volatilities in the output gap. Compare this efficient frontier with the one in figure (9.8), which corresponds to a higher $\lambda=1$ (and $k=0.01$ ). Given the higher weight associated with inflation volatility, moving toward the optimal commitment policy involves lowering inflation volatility substantially at the cost of higher output gap volatility. 


\section{Conclusions}

This paper presents a model in which monetary authority is a committee whose members have finite terms and are gradually replaced by new committee members. Older and younger generations of MPC members set monetary policy by engaging in a utilitarian bargaining process. An MPC entirely composed of old members replicates the monetary outcomes under a single central banker who sets policy under commitment. The other extreme is a committee fully composed of young or incoming members, which would replicate the results under discretion. Any combination in between will generate results that are often referred to as imperfect credibility in the literature. Thus, this model suggests an institutional reason to justify imperfect credibility and imposes the frequency with which promises are broken. This frequency has hitherto been exogenously assumed by the imperfect credibility literature.

The rate at which MPC members are replaced -the churning rate- has important welfare implications: slower replacement rate of MPC members results in improved welfare since it brings the equilibrium policy closer to the full commitment case. I also compare voting to a more consensus-seeking approach to MPC decision-making. Under a voting procedure the change in welfare is discrete. If the majority of MPC members are old, the equilibrium policy will be that under commitment. Whereas the resulting policy will be equivalent to the discretionary outcome if the majority of members are young. On the other hand, the changes in welfare are continuous if decisions are made in a more collegial manner, such as bargaining. In this case, the lower the churning rate, the closer the expected loss will be to the commitment policy.

Furthermore, calibrating the model reveals that the rate of change of welfare with the degree of commitment is highly sensitive to the parameters used, particularly the subjective weight of inflation vs. output gap volatility and the slope of the NKPC. Under the benchmark calibration (Woodford (1999)), welfare gains increase roughly linearly with the degree of commitment. However, an alternative calibration suggested by McCallum and Nelson (2004) results in a convex increase in welfare gains with the degree of commitment. This result indicates that the shape of welfare gains and its dependence on the degree of commitment may not be an inherent characteristic of the problem, but they might depend on calibration. This finding explains the apparent discrepancy between previous studies which had reported convexity or concavity of welfare gains in the degree of commitment. 


\section{Tables}

Table 8.1: Calibration of Parameters

\begin{tabular}{llcc}
\hline Variable & Description & $(1)$ & $(2)$ \\
\hline \hline$\sigma$ & Intertemporal elasticity of substitution in consumption & 1.5 & - \\
$\beta$ & Discount factor & 0.99 & 0.99 \\
$\kappa$ & output gap elasticity of inflation & 0.1 & $0.01,0.1$ \\
$\lambda$ & relative weight on the output gap in the welfare function & 0.048 & $0.001,0.1$ \\
$\rho$ & autoregression parameter for $u_{t}$ & 0 & 0.80 \\
\hline
\end{tabular}

This table presents the benchmark calibration of the model, following Woodford (1999) in column (1) and the alternative calibration suggested by McCallum and Nelson (2004) in column (2). 


\section{Figures}

Figure 9.1: Dynamic Response to a Cost-push Shock
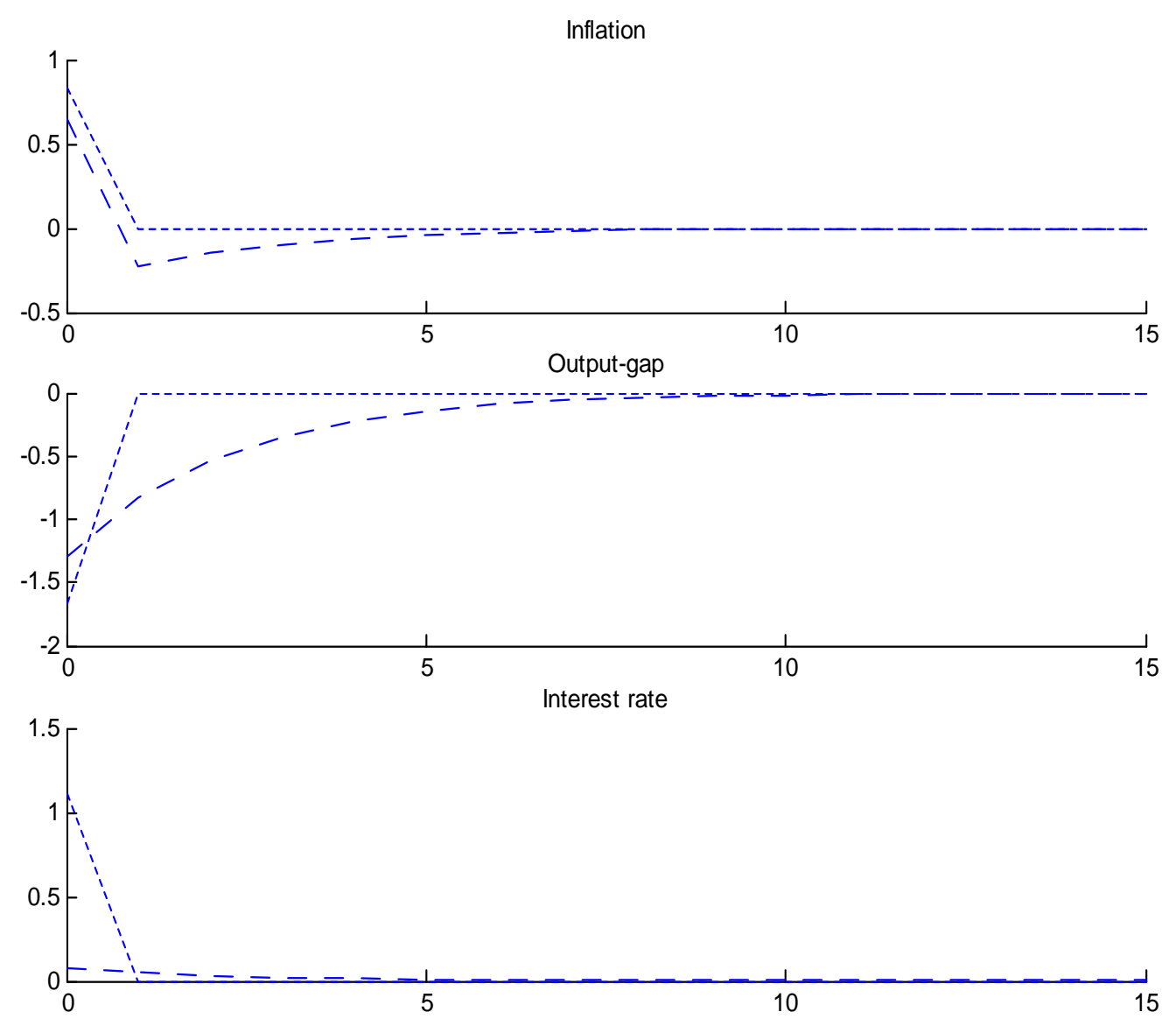

This figure shows the dynamic responses to a one standard deviation, uncorrelated cost-push shock under commitment (dashed line) and discretion (dotted line). The parameters are calibrated according to the benchmark presented in table (8.1). 
Figure 9.2: Dynamic Response to a Cost-push Shock: Committee
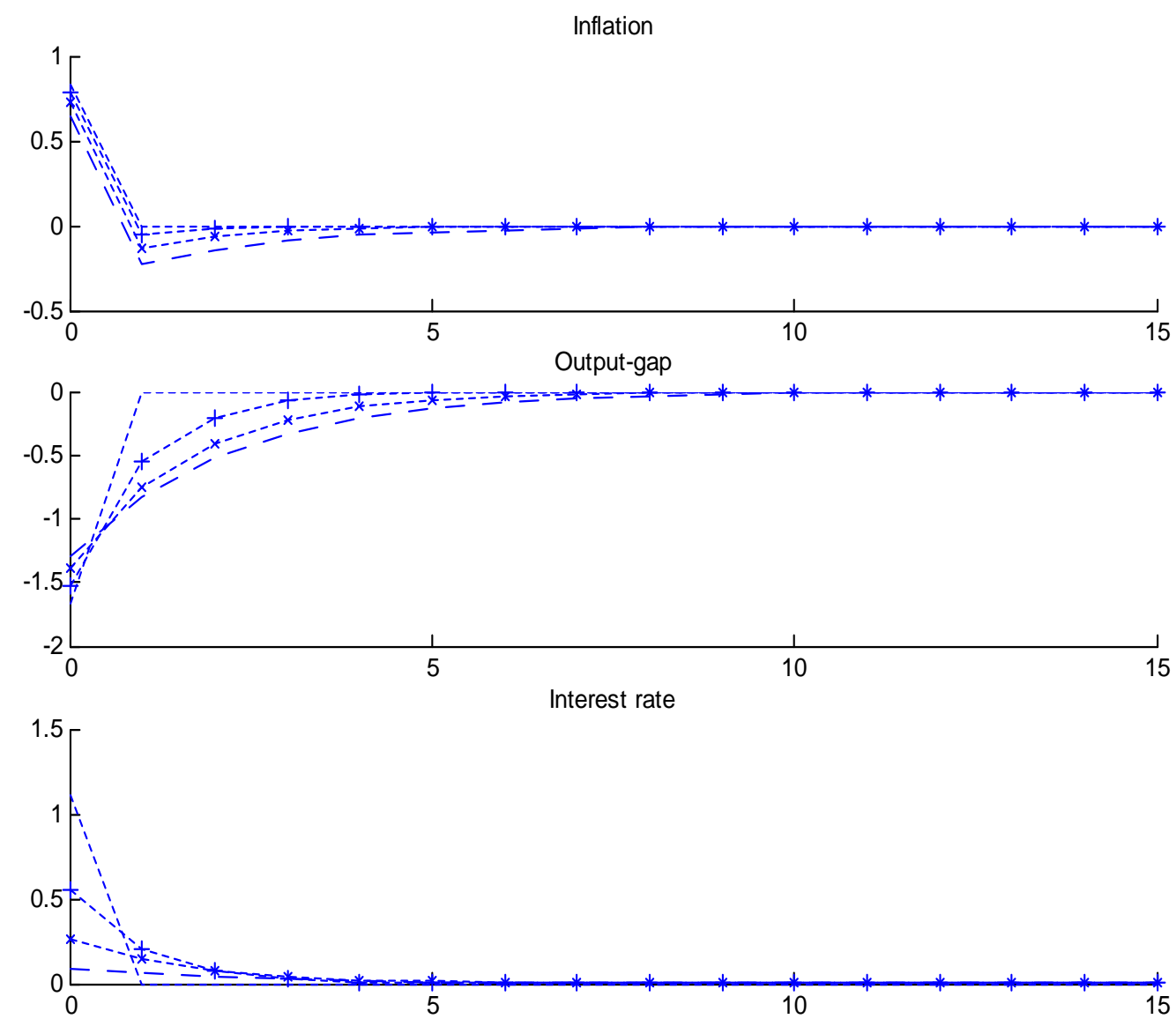

This figure shows the dynamic responses to a one standard deviation, uncorrelated cost-push shock in an MPC with various majorities. The parameters are calibrated according to the benchmark presented in table (8.1). The dotted-plus line corresponds to $\alpha=0.5$, the dottedcross line corresponds to $\alpha=0.75$. Commitment and discretion responses are represented by the dashed line and the dotted line respectively. The path of inflation and output gap in a two person committee $(\alpha=0.5)$ is roughly halfway between commitment and discretion. The responses under $\alpha=0.75$ are much closer to commitment outcomes. 
Figure 9.3: Dynamic Response to a Persistent Cost-push Shock
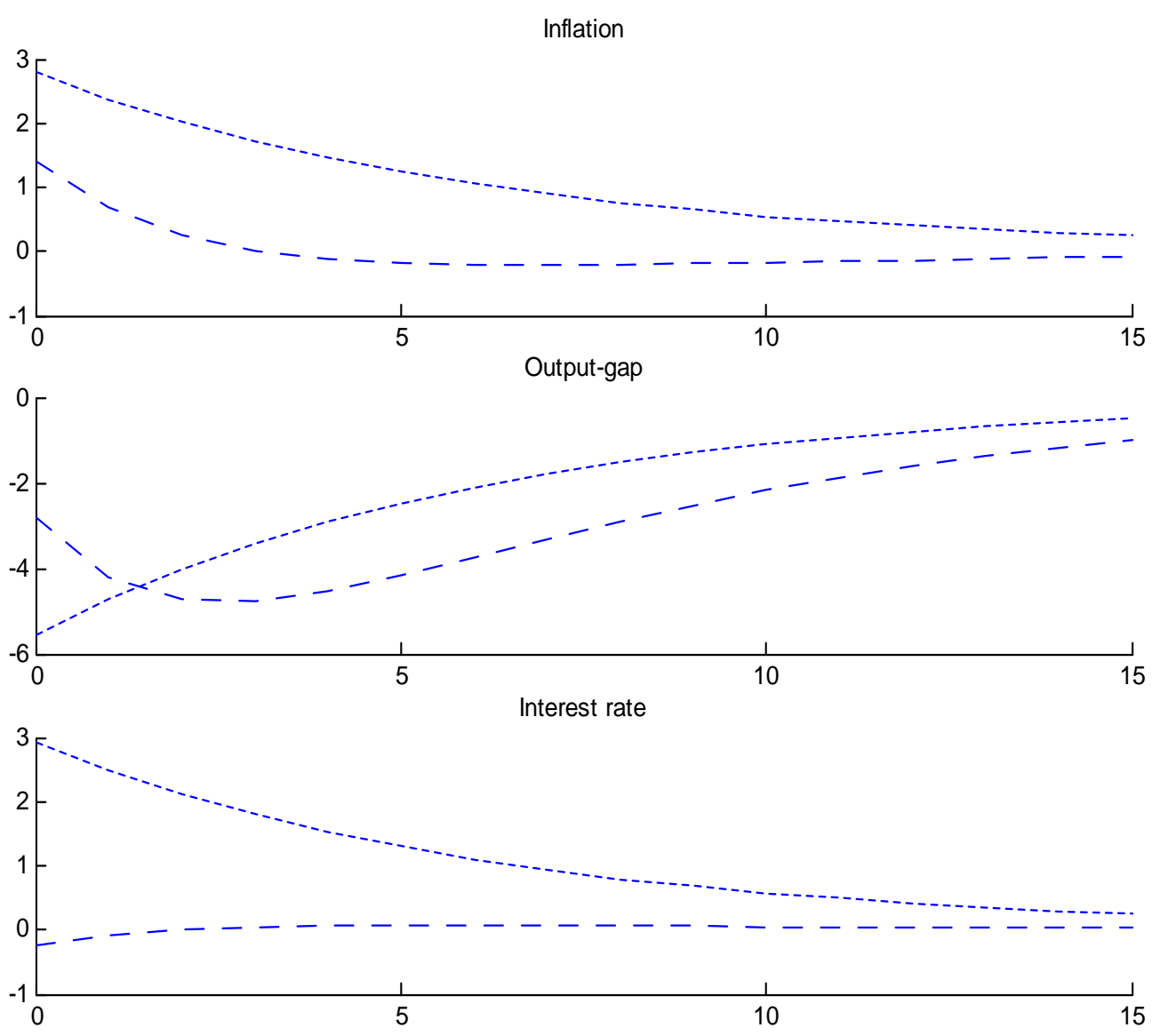

This figure shows the dynamic responses to a one standard deviation cost-push shock with persistence $(\rho=0.8)$ under commitment (dashed line) and discretion (dotted line). Other parameters are calibrated according to the benchmark presented in table (8.1). 
Figure 9.4: Dynamic Response to a Persistent Cost-push Shock: Committee
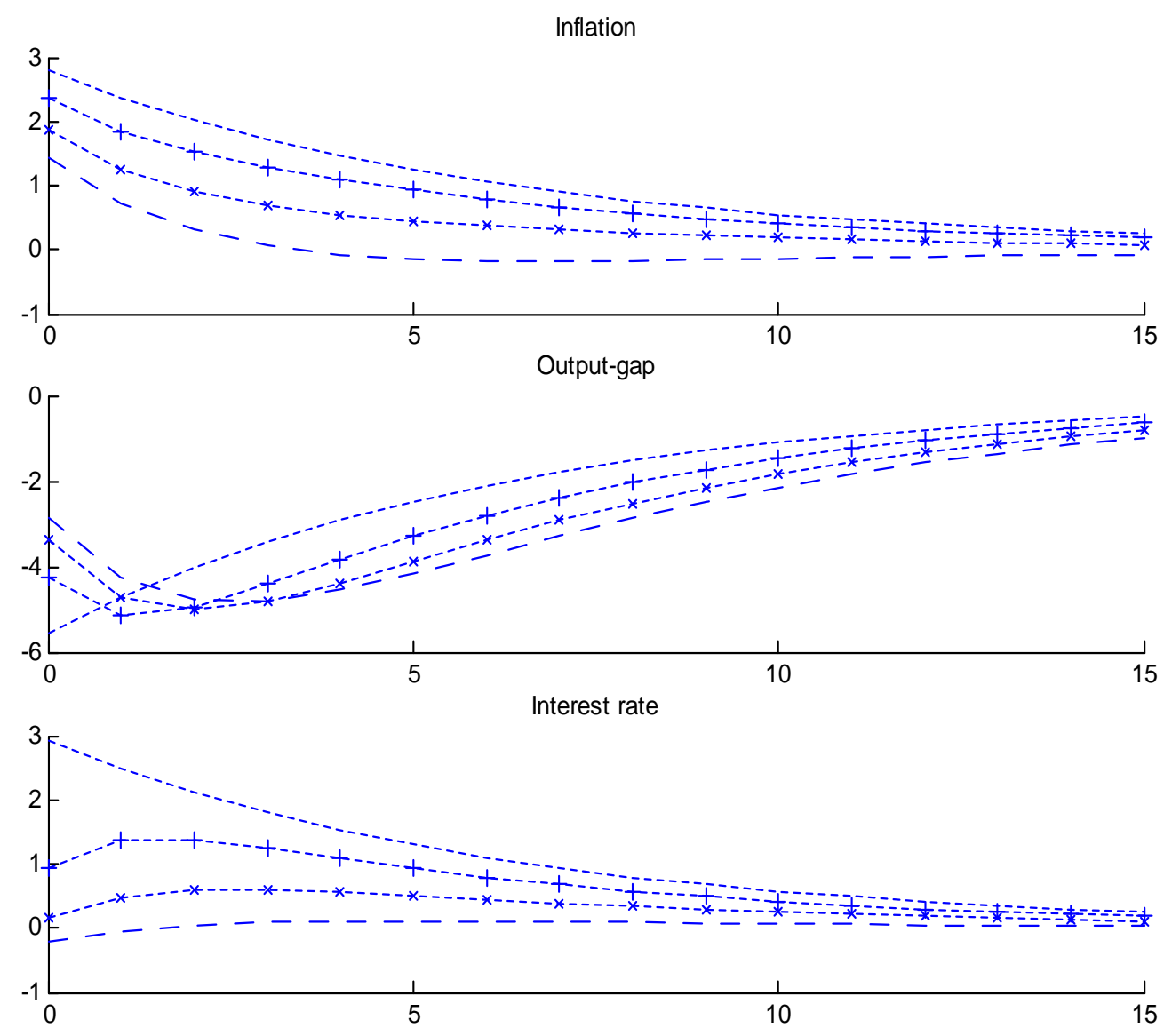

This figure shows the dynamic responses to a one standard deviation, persistent cost-push shock $(\rho=0.8)$ in an MPC with various majorities. The other parameters are calibrated according to the benchmark presented in table (8.1). The dashed-plus line corresponds to $\alpha=0.5$, the dashed-cross line corresponds to $\alpha=0.75$. Commitment and discretion responses are represented by the dashed line and the dotted line respectively. The path of inflation and output gap in a two-person committee $(\alpha=0.5)$ is roughly halfway between commitment and discretion. The responses under $\alpha=0.75$ are much closer to commitment outcomes. 
Figure 9.5: Variation of Expected Loss with $\alpha$

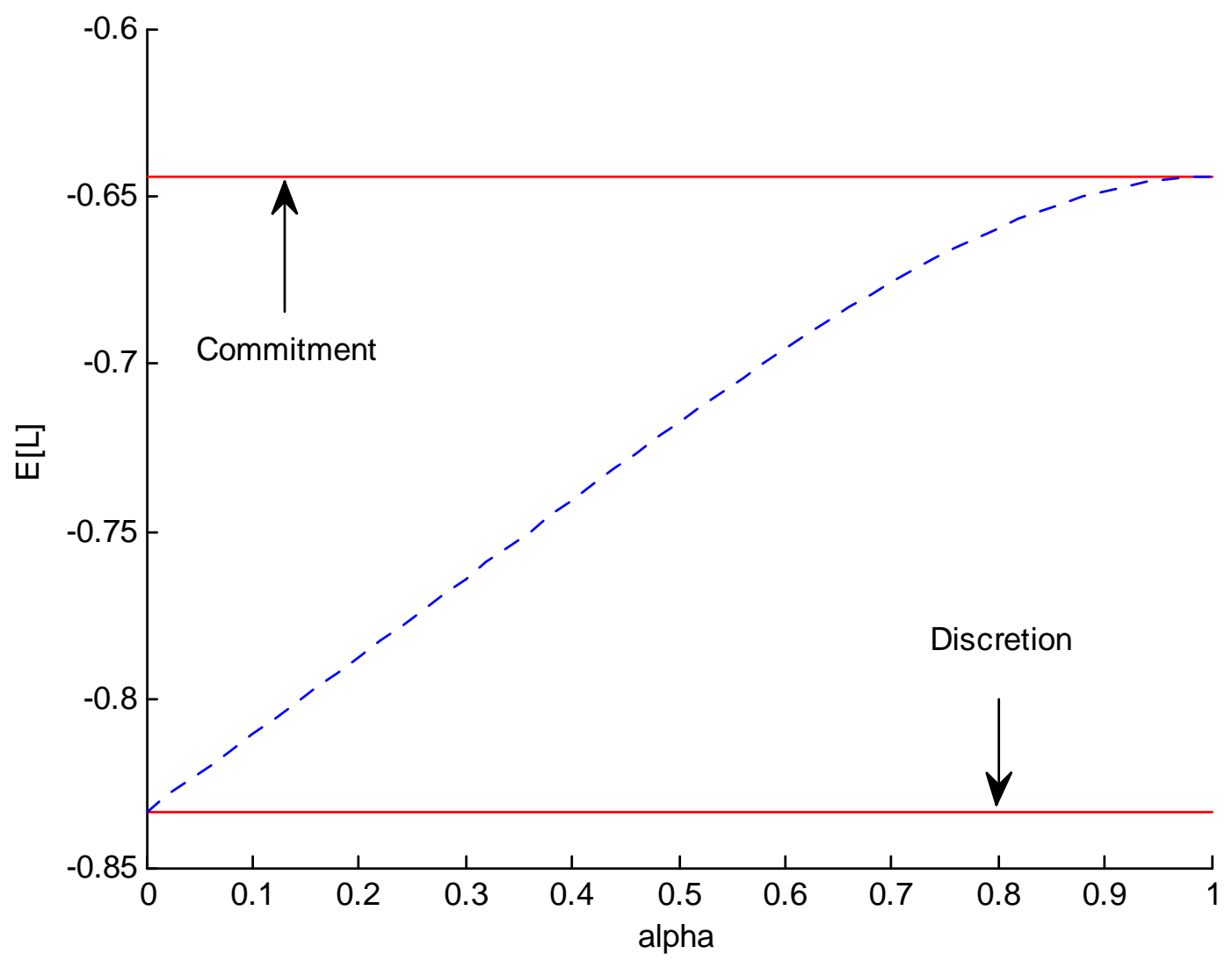

This figure shows the variation of expected loss to society with $\alpha$, or the proportion of old MPC members under benchmark calibration. The two solid lines show the expected loss under commitment and discretion. When $\alpha=0$ (churning is 100\%), the loss to society is the same as in discretionary monetary policy. When $\alpha=1$, the loss to society is the same as under commitment. 
Figure 9.6: Variation of Expected Loss with $\alpha$ - McCallum and Nelson (2004) Calibration

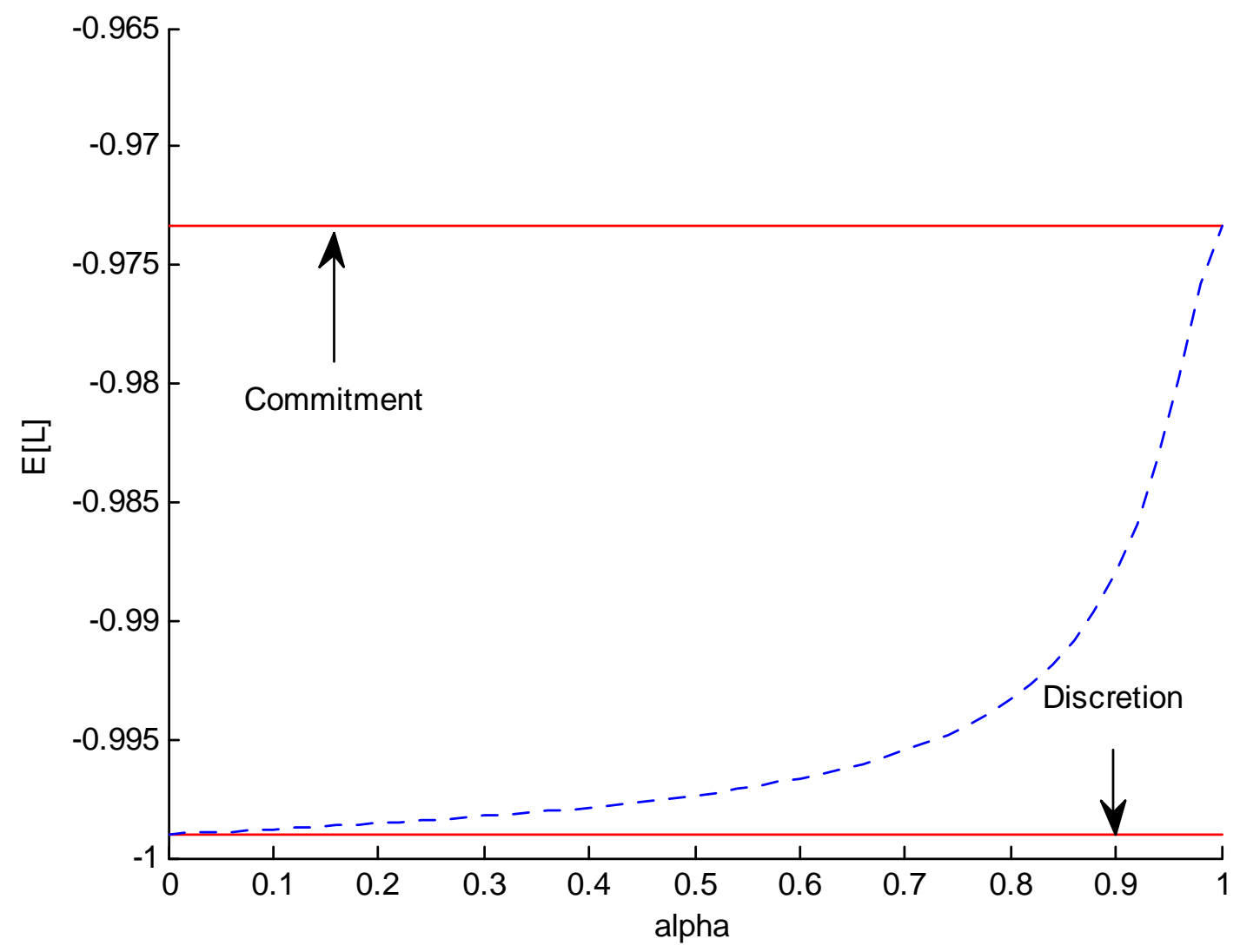

This figure shows the variation of expected loss to society with $\alpha$, or the proportion of old MPC members under the alternative McCallum and Nelson (2004) calibration $(\lambda=0.1, k=0.01)$. The two solid lines show the expected loss under commitment and discretion. When $\alpha=0$ (churning is $100 \%$ ), the loss to society is the same as in discretionary monetary policy. When $\alpha=1$, the loss to society is the same as under commitment. 
Figure 9.7: Efficient Frontier - Benchmark Calibration

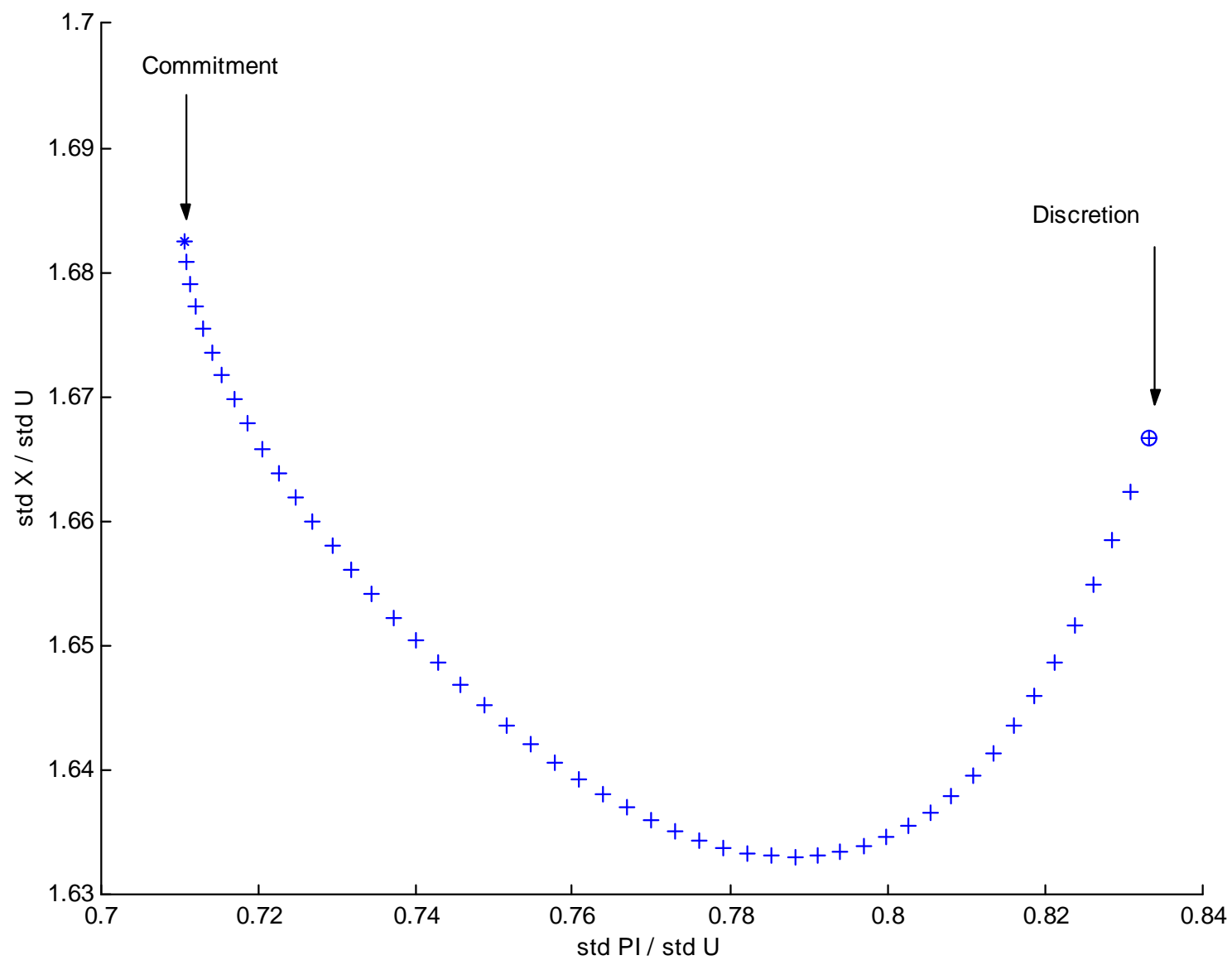

This figure shows the efficient frontier under the benchmark calibration. Each point corresponds to a value of $\alpha$ between 0 and 1 . The y-axis shows the standard deviation of output gap and the $\mathrm{x}$-axis the variation of standard deviation of inflation. The parameters are calibrated according to the benchmark case in table (8.1). 
Figure 9.8: Efficient Frontier - McCallum and Nelson (2004) Calibration

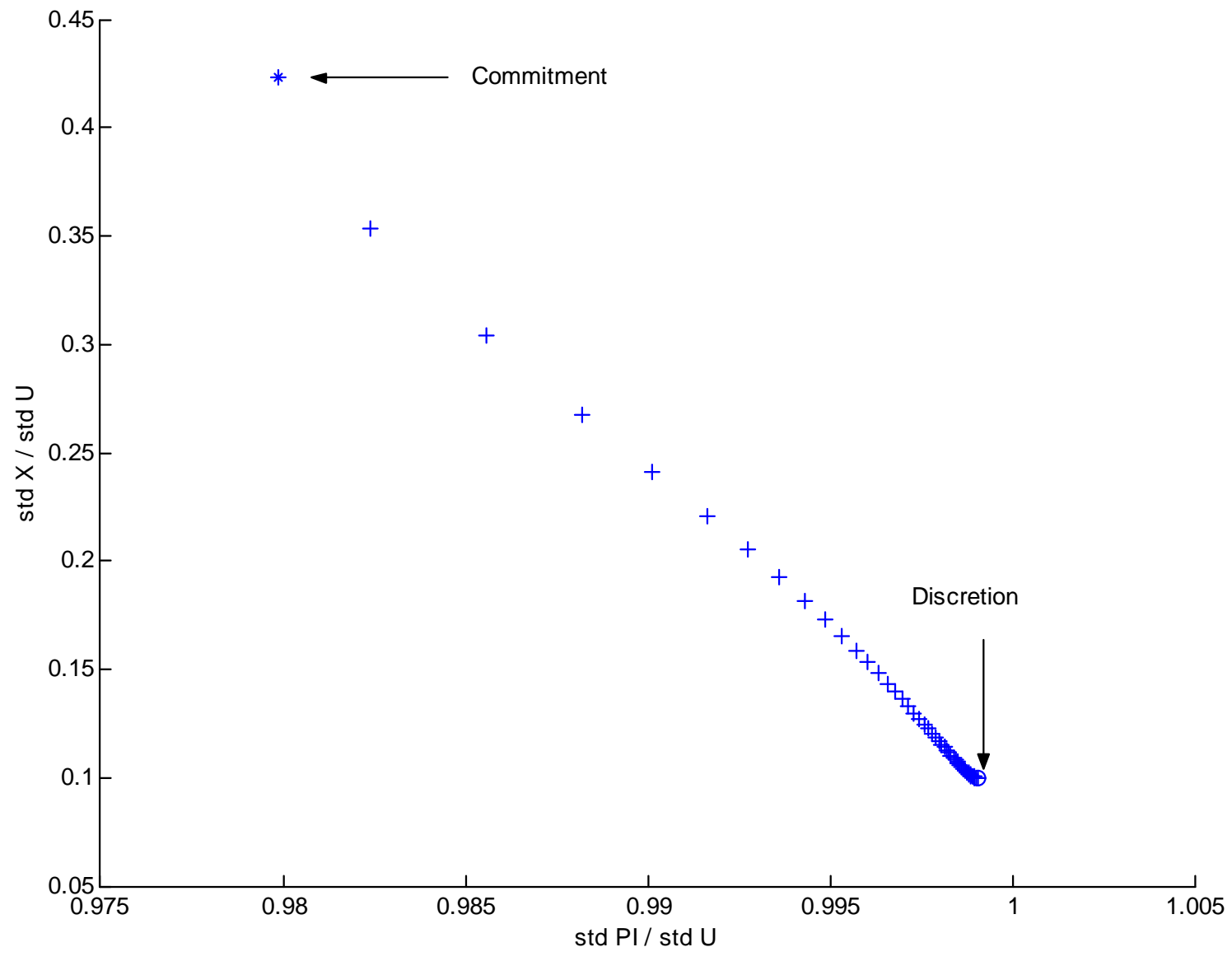

This figure shows the efficient frontier under the benchmark calibration. Each point corresponds to a value of $\alpha$ between 0 and 1 . The y-axis shows the standard deviation of output gap and the $\mathrm{x}$-axis the variation of standard deviation of inflation. The parameters are calibrated according to the alternative calibration suggested by McCallum and Nelson (2004) $\lambda=0.1, k=0.01$. 


\section{References}

Aksoy, Y., P. De Grauwe, and H. Dewachter (2002): "Do asymmetries matter for European monetary policy?," European Economic Review, 46(3), 443-469.

Barro, R. J., and D. B. Gordon (1983): "Rules, discretion and reputation in a model of monetary policy," Journal of Monetary Economics, 12(1), 101-121.

Blinder, A. S. (1998): Central Banking in Theory and Practice. MIT Press, Cambridge, MA.

Calvo, G. A. (1983): "Staggered prices in a utility-maximizing framework," Journal of Monetary Economics, 12(3), 383-398.

Chari, V. V., and P. J. Kehoe (1990): "Sustainable Plans," Journal of Political Economy, 98(4), 783-802.

Clarida, R., J. Gali, and M. Gertler (1999): "The Science of Monetary Policy: A New Keynesian Perspective," Journal of Economic Literature, 37(4), 16611707.

Debortoli, D., and R. Nunes (2007): "Loose Commitment," in FRB International Finance Discussion Paper No. 916.

Erceg, C. J., And A. T. Levin (2006): "Optimal monetary policy with durable consumption goods," Journal of Monetary Economics, 53(7), 1341-1359.

Gali, J., and M. Gertler (1999): "Inflation dynamics: A structural econometric analysis," Journal of Monetary Economics, 44(2), 195-222.

Gerlach-Kristen, P. (2006): "Heterogeneity in Price Stickiness and the Real Effects of Monetary Shocks," European Economic Review, 50(2), 487-507.

(2008): "The role of the Chairman in setting monetary policy: Individualistic vs autocratically collegial MPCs," International Journal of Central Banking, $4(3), 119-143$.

Hahn, V., And H. Gersbach (2001): "Should the Individual Voting Records of Central Bankers be Published?," Deutsche Bundesbank Economic Studies, (2).

Hefeker, C. (2003): "Federal Monetary Policy," Scandinavian Journal of Economics, 105(4), 643-659.

JudD, K. L. (1985): "Short-run Analysis of Fiscal Policy in a Simple Perfect Foresight Model," Journal of Political Economy, 93(2), 298-319.

KarA, H. (2003): "Optimal Monetary Policy, Commitment, and Imperfect Credibility," in Central Bank of Turkey Discussion Paper No. 61. 
King, R., And A. L. Wolman (1999): "What Should the Monetary Authority Do When Prices Are Sticky?," in Monetary Policy Rules. National Bureau of Economic Research.

Kurozumi, T. (2008): "Optimal sustainable monetary policy," Journal of Monetary Economics, 55(7), 1277-1289.

Kydland, F. E., and E. C. Prescott (1977): "Rules Rather Than Discretion: The Inconsistency of Optimal Plans," Journal of Political Economy, 85(3), 473-491.

Lucas, R. J., And N. L. Stokey (1983): "Optimal fiscal and monetary policy in an economy without capital," Journal of Monetary Economics, 12(1), 55-93.

Mas-Colell, A., M. Whinston, and J. Green (1995): Microeconomic Theory. Oxford University Press.

McCallum, B. T., and E. Nelson (2004): "Timeless perspective vs. discretionary monetary policy in forward-looking models," Review, Federal Reserve Bank of St. Louis, pp. 43-56.

Persson, M., T. Persson, and L. Svensson (2006): "Time consistency of fiscal and monetary policy: a solution," Econometrica, 74(1), 193-212.

Roberts, J. M. (1995): "New Keynesian Economics and the Phillips Curve," Journal of Money, Credit and Banking, 27(4), 975-984.

Rotemberg, J. (1982): "Monopolistic Price Adjustment and Aggregate Output," Review of Economic Studies, 49(4), 517-531.

Rotemberg, J., and M. Woodford (1999): "The Cyclical Behavior of Prices and Costs," in NBER Working Papers No. 6909.

Rudebusch, G., and L. E. O. Svensson (1999): "Policy Rules for Inflation Targeting," in Monetary Policy Rules. National Bureau of Economic Research.

Schaumburg, E., and A. Tambalotti (2007): "An investigation of the gains from commitment in monetary policy," Journal of Monetary Economics, 54(2), 302324.

Sibert, A. (2003): "Monetary Policy Committees: Individual and Collective Reputations," Review of Economic Studies, 70(3), 649-665.

TAylor, J. B. (1980): "Aggregate Dynamics and Staggered Contracts," Journal of Political Economy, 88(1), 1-23.

Walsh, C. (2003): Monetary Theory and Policy. MIT Press, Cambridge, MA, second edn.

Woodford, M. (1999): "Commentary: How Should Monetary Policy be Conducted in an Era of Price Stability," in New Challenges for Monetary Policy, ed. by P. A. et al. Fed. Reserve Bank Kansas City, Kansas City. 
Woodford, M. (2003): Interest and Prices. Foundations of a Theory of Monetary Policy. Princeton University Press, Princeton and Oxford. 